\title{
DA COMISSÃO NACIONAL DA VERDADE AO DIREITO À VERDADE: A VALIDAÇÃO DISCURSIVA DAS COLEÇÕES NAS BIBLIOTECAS
}

\section{LA COMISIÓN NACIONAL DE VERDAD AL DERECHO A LA VERDAD: LA VALIDACIÓN DISCURSIVA DE COLECCIONES EN BIBLIOTECAS}

Kelly Pereira de Lima - kellybibli@yahoo.com.br Mestranda do Programa de Pós-Graduação em Ciência da Informação da Universidade Federal Fluminense (UFF).

Sarah Miglioli - smiglioli@gmail.com Doutoranda do Programa de Pós-Graduação em Ciência da Informação do Instituto Brasileiro de Informação em Ciência e Tecnologia/Universidade Federal do Rio de Janeiro (IBICT/UFRJ).

Clóvis Ricardo Montenegro de Lima - clovismlima@gmail.com Pós-doutor em Ciência da Informação pelo Instituto Brasileiro de Informação em Ciência e Tecnologia (IBICT). Pesquisador do Instituto Brasileiro de Informação em Ciência e Tecnologia/Universidade Federal do Rio de Janeiro (IBICT/UFRJ).

\begin{abstract}
RESUMO
Introdução: Analisa o conceito de informação, verdade e validade discursiva. Propõe a formalização e revisão da Política de Desenvolvimento de Coleção em vista da ética informacional, Comissão Nacional da Verdade e censura.

Objetivo: Discute o posicionamento do agir do profissional da informação, de forma socialmente responsável, diante do novo cenário e atuação por meio de uma política de desenvolvimento de coleção com decisões éticas de quais verdades irão fazer parte do acervo

Metodologia: $O$ marco teórico deste artigo se propõe a analisar a complexidade da questão da verdade por meio de Jürgen Habermas e Michel
\end{abstract}


Foucault, sob a égide da filosofia da linguagem e da consciência, respectivamente. Primeiramente aborda sob o foco crítico a relação entre informação e verdade. Posteriormente, serão trazidos os fatos históricos da Comissão Nacional da Verdade, a verdade nas bibliotecas, e por último, a validação discursiva do desenvolvimento de coleções.

Resultados: Através de Habermas, o marco teórico se utiliza da aprendizagem intersubjetiva por meio da linguagem, ou seja, no discurso residente na possibilidade do entendimento mútuo e da prevalência da verdade. Ter coragem de dizer e procurar a verdade, sugeridas por Foucault, são posturas que compõe a ética de um profissional que é solidário com a dignidade humana de cada integrante de sua comunidade.

Conclusões: O profissional da informação tem uma responsabilidade social, por ser a incorporação da alma de uma sociedade e de seu pressuposto democrático. Sua relevância encontra-se no fato de reger o potencial inerente às coleções de maneira a promover a verdade, sem a qual sua atuação perderia o viés moral e ético.

Palavras-chave: Verdade. Comissão Nacional da Verdade. Desenvolvimento de Coleções. Profissional da Informação.

\section{INTRODUÇÃO}

Este artigo se insere nos estudos acerca das configurações sociais e das políticas de informação. Através do processo de reconstrução histórica e redescoberta da verdade, analisa-se o processo da dinâmica da informação.

No âmbito da esfera pública, investiga-se a partir da reconstrução histórica, representada pelas ações da Comissão Nacional da Verdade, mais precisamente as relações entre informação, verdade e o desenvolvimento de coleções.

No Brasil, as Comissões da Verdade instauram aura de redemocratização e reconstrução histórica para descortinar a verdade dos fatos acontecidos durante regime ditatorial em seu passado recente. Procura-se nessas ações encontrar os responsáveis pelo descumprimento aos direitos humanos durante o regime militar que se instaurou no Brasil, entre as décadas de 60 a 80.

Passa então a averiguar informações para alcançar uma demonstração consensual da verdade. Para além da restauração da 
memória histórica coletiva e individual dos indivíduos vitimizados, tal período caracterizou como fértil campo de ação comunicativa na esfera do discurso.

O marco teórico deste artigo se propõe a analisar a complexidade da questão da verdade por meio de Jürgen Habermas e Michel Foucault, sob a égide da filosofia da linguagem e da consciência, respectivamente. Primeiramente aborda sob o foco crítico a relação entre informação e verdade. Posteriormente, serão trazidos os fatos históricos da Comissão Nacional da Verdade, a verdade nas bibliotecas, e por último, a validação discursiva do desenvolvimento de coleções.

\section{INFORMAÇÃO E VERDADE: UMA ABORDAGEM CRÍTICA}

A Informação é objeto de pesquisa de muitas áreas do saber. Sua onipresença e multiplicidade de interpretações sobre seu significado no mundo real a torna elemento complexo. Uma definição que abrange sua plenitude ainda não foi possível, embora alguns teóricos a tenha delimitado dentro do seu campo de conhecimento.

Na Ciência da Informação, Buckland (1991) apresenta três sentidos para a informação, podendo ser entendida como processo, conhecimento e coisa. A informação como processo acontece na ação da fala, na comunicação, quando uma pessoa é informada, e aquilo que conhece é alterado. No conhecimento, a informação é o que é percebido ou transmitido na informação como processo. Quando coisa, a informação é materializada em objeto informativo.

Currás (1993 apud MACHADO, 2003) menciona que a informação não existe por si mesma, mas é propriedade relacionada entre fontes e receptores, por meio de fenômeno, acontece pela comunicação, ou como processo, quando é registrada em algum suporte informacional.

Pela comunicação a informação é veiculada, sendo a linguagem elemento e via de acesso ao mundo, criando vínculo com outros 
indivíduos e mediando as relações sociais. Para Bannell (2009) "Não temos acesso à realidade senão pela mediação linguística; nossa compreensão da realidade é sempre atrelada à linguagem." A linguagem natural pode ser utilizada como meio de transmissão de informações ou fonte de integração social de modo que o alter conecta seus planos e ações aos planos e ações de ego, resultando diferentes tipos de interações (HABERMAS, 1990). No agir estratégico, a influência dos atores é uns sobre os outros e sobre a situação da ação; e no agir comunicativo a força consensual do entendimento torna-se efetiva para a coordenação das ações, e os atores participantes tentam definir cooperativamente os seus planos de ação, levando-se em conta mutuamente. $\mathrm{O}$ que distingue o agir comunicativo do agir estratégico é a coordenação da ação apoiada na força racionalmente motivadora de atos de entendimento, que se manifesta nas condições requeridas para um acordo obtido comunicativamente, e não na racionalidade dos planos individuais (HABERMAS, 1990).

Como processo, a informação é contextual e representa a realidade. É estabilizada quando se materializa em um suporte, sendo ele analógico ou digital, "[...] instrumento para promover a circulação social do conhecimento [...]" (ORTEGA; LARA, 2010). Paul Otlet emprega o termo "documento" ou "unidade documentária" para denotar objetos informativos que contenham "signos representativos de certos dados intelectuais" (OTLET, 1996 apud ORTEGA; LARA, 2010). Para Briet (1951), documento é todo índice concreto ou simbólico, conservado ou registrado a fim de representar ou provar um fenômeno físico ou intelectual. Nesse contexto, os objetos não são na sua essência documentos, mas se transformam em registros, se processados com finalidades de fornecer informação (BUCKLAND, 1991). Murguia (2010, p. 127) considerava o documento como dispositivo de validação, que "[...] é sustentado e sustenta os discursos que o incluem, se materializa nos objetos e age institucionalmente [...]", como uma construção social. 
Os enunciados expostos são divulgados e submetidos ao crivo de uma comunidade de relevância de uma área do saber, entre os pares, ou grupo social. As argumentações apresentadas podem elevar os enunciados como verdade. Habermas (2004a) afirma que a verdade é como uma propriedade inalienável dos enunciados e,

[...] um enunciado seria verdadeiro precisamente se e somente se pudesse resistir, sob os exigentes pressupostos pragmáticos dos discursos racionais, a todas as tentativas de invalidação, ou seja, se pudesse ser justificado numa situação epistêmica ideal. (HABERMAS, 2004a, p. 46).

A noção de verdade é temporal, e não universal. No transcorrer dos marcos históricos, as verdades acompanham os cenários políticos, econômicos e sociais. A verdade pode ser posta em prova, de modo procedural, sob condições de práxis de argumentação. Habermas (2004a) propõe pressupostos idealizantes, como publicidade e inclusão de todos envolvidos; distribuição equitativa dos direitos de comunicação; cenário que admite apenas a força não-coerciva do melhor argumento; e o proferimento de todos os participantes.

Para atingir o nível de verdade, são proferidos discursos com a prerrogativa de se chegar ao assentimento ou consenso. As evidências apresentadas no contexto de justificação devem bastar para autorizar a levantar pretensões de verdade, existindo uma relação interna entre verdade e justificação (HABERMAS, 2004a).

Os discursos são como máquinas de lavar: filtram aquilo que é racionalmente aceitável para todos. Separam as crenças questionáveis e desqualificadas daquelas que, por um certo tempo, recebem licença para voltar as status de conhecimento nãoproblemático. (HABERMAS, 2004b, p. 63)

Os discursos narrativos na prerrogativa da justificação, para o alcance da validação, são recursos pedagógicos de desenvolvimento de exposições de argumento e desenvolvimento moral. As estruturas 
cognitivas do indivíduo se transformam e se diferenciam, conseguindo resolver melhor do que anteriormente a mesma espécie de problemas e conflitos de ação moralmente relevante (KOHLBERG apud HABERMAS, 1989).

A ética do discurso de Habermas (1989) vai ao encontro da concepção construtiva da aprendizagem pelo desenvolvimento moral, na medida em que compreendemos a formação discursiva da vontade (assim como a argumentação em geral) como uma forma de reflexão do agir comunicativo; e na medida que exige, para a passagem do agir para o discurso, há uma mudança de atitude.

O agir comunicativo depende do uso da linguagem dirigida ao entendimento, para Habermas (1990, p. 72, grifo do autor),

[...] os atores participantes tentam definir cooperativamente os seus planos de ação, levando em conta uns aos outros, no horizonte de um mundo da vida compartilhado e na base de interpretações comuns de situação. Além disso, eles estão dispostos a atingir esses objetivos mediados da definição da situação e da escolha dos fins assumindo o papel de falantes e ouvintes, que falam e ouvem através de processo de entendimento.

No âmbito do humanismo, Foucault também aborda o tema da veracidade ao tratar da parresía. Foucault (2014) propõe uma eticidade, uma ética do falar, do expressar. O autor traz a ideia da dignidade de dar voz, sem mediação, falar em seu próprio nome. Diferente da retórica, na parresía de Foucault (2014, p. 4), "o indivíduo se constitui e é constituído pelos outros como sujeito que pronuncia um discurso de verdade."

O dizer a verdade sobre si mesmo sempre "[...] foi uma atividade conjunta, uma atividade com os outros, e mais precisamente uma atividade com um outro, uma pratica a dois. [...] O estatuto desse outro é variável, portanto. [...] Pode ser também uma espécie de conselho político." (FOUCAULT, 2014, p. 6-7). O conceito assume que cada sujeito é uma potência (força) e suas atitudes são ações de forças e 
jogos (resistência e aceitações dos participantes) resultando em papeis e atitudes. O ser e estar são exercícios de forças.

Foucault (2014) retoma e empreende a análise da parresía no campo das praticar políticas, empregando o falar a verdade com um valor positivo, sem dissimulação nem reservas.

Para que haja parresía é preciso que, dizendo a verdade, se abra, se instaure e se enfrente o risco de ferir o outro, de irritá-lo, de deixá-lo combativo e de suscitar de sua parte algumas condutas que podem ir até a mais extrema violência. É portanto a verdade, no risco da violência. [...] De onde essa nova característica da parresía: ela implica uma certa forma de coragem, coragem cuja forma mínima consiste em que o parresiasta se arrisque a desfazer, a deslindar essa relação com o outro que tornou possível precisamente seu discurso. De certo modo, o parresiasta sempre corre o risco de minar essa relação que é a condição de possibilidade do seu discurso. (FOUCAULT, 2014, p. 12).

A ética da parresía engloba esse falar apesar das consequências, que resgata a dimensão humana no valor da eticidade. Podemos considerar isso para pensar a veracidade, nesse sentido, assim como Habermas também se preocupa com a verdade, a validação da verdade e agir comunicativo.

\section{COMISSÃO NACIONAL DA VERDADE E A VERDADE NAS BIBLIOTECAS}

O fato histórico das Comissões da Verdade como espaço de ação da linguagem, remetem às relações de informação, seus registros documentais e a veracidade. Torna-se importante tratar da Comissão Nacional da Verdade, do contexto histórico e da validação de informação que compuseram o cenário desse processo. As informações foram colhidas através da página governamental da Comissão (cnv.gov.br) e a Lei 12.528, de 2011, que cria a Comissão Nacional da Verdade no âmbito da Casa Civil da Presidência da República do Brasil. A Comissão Nacional da Verdade foi criada pela Lei citada em 2011 e 
Kelly Pereira de Lima; Sarah Miglioli; Clóvis Ricardo Montenegro de Lima Da comissão nacional da verdade ao direito à verdade: a validação discursiva das coleções nas bibliotecas

instituída em 2012. A Comissão tem como fim verificar e investigar violações de Direitos Humanos ocorridas entre os anos de 1946 a 1988 no Brasil.

Segundo a lei (BRASIL, 2011), a Comissão é composta de forma pluralista, integrada por sete membros, designados pelo Presidente da República, dentre brasileiros de reconhecida idoneidade, conduta ética, e respeito aos direitos humanos.

São objetivos da Comissão Nacional da Verdade esclarecer os fatos e as circunstâncias dos casos de graves violações de direitos humanos; promover o esclarecimento circunstanciado dos casos de torturas, mortes, desaparecimentos forçados, ocultação de cadáveres e sua autoria, ainda que ocorridos no exterior; identificar e tornar públicos as estruturas, os locais, as instituições e as circunstâncias relacionadas à prática de violações de direitos; encaminhar aos órgãos públicos competentes toda e qualquer informação obtida que possa auxiliar na localização e identificação de corpos e restos mortais de desaparecidos políticos; colaborar com todas as instâncias do poder público para apuração de violação de direitos humanos; recomendar a adoção de medidas e políticas públicas para prevenir violação de direitos humanos, assegurar sua não repetição e promover a efetiva reconciliação nacional; e promover, com base nos informes obtidos, a reconstrução da história dos casos de graves violações de direitos humanos, bem como colaborar para que seja prestada assistência às vítimas de tais violações.

[...] não podemos depositar muitas expectativas na capacidade da revelação da verdade oficial servir para "fechar o livro" da história e encerrar o passado num capítulo. Existem vários argumentos que dizem que a revelação da verdade preenche uma necessidade social de confirmar oficialmente aquilo que foi durante muito tempo negado; que a 'verdade' reintegra as vítimas na sociedade, através do reconhecimento do seu sofrimento e oferecendo uma forma de justiça distributiva ou social, contribuindo com recursos não convencionais para promover a conscientização social, a memória coletiva, a solidariedade e a superação de 
baixa autoestima. Pode ser que o esquecimento seletivo seja parte do processo de produção histórica, constituindo os silêncios descritos por Trouillot; mas esquecer o significado de eventos passados pode ser como perder a bússola moral. A verdade também tem sido vista como uma forma de 'justiça como reconhecimento' ou 'justiça compensatória', que restabelece o sentido de justiça outrora quebrado. As comissões da verdade oficiais também já têm sido valorizadas como peças centrais nos 'processos de refundação histórica' quando existe uma ruptura simbólica e moral com um passado obscuro. Elas podem contribuir para 'estabelecer um consenso sobre os limites do intolerável. (BRITO, 2009, p. 77).

A Ditadura militar no Brasil foi o regime que permaneceu de 1964 a 1985, e possuía caráter nacionalista e autoritário. Instaura-se a partir de um golpe militar que retira do governo o presidente eleito João Goulart, e perdura por vinte e um anos. O governo da ditadura militar então cria diversas normas e decretos, os Atos Institucionais, que estavam acima de todas as demais normas e até mesmo da Constituição. Os Atos Institucionais eram usados como instrumentos de legitimação e legalização das ações políticas deste governo, instaurando para seu próprio governo formas de poderes extraconstitucionais, sob a ideia de combater a "corrupção e a subversão". Esse processo culmina com o Al-5 de 1968, que veio a vigorar por dez anos.

A partir de então liberdades civis foram anuladas, com a criação de um código de processo penal militar que permitia que o Exército brasileiro e a Polícia Militar prendessem indivíduos considerados suspeitos. Foi nesse período que milhares de pessoas, entre ativistas políticos, sindicalistas e outros civis desapareceram, ou foram torturados e mortos.

A partir de 1979, o governo brasileiro promulgou a Lei da Anistia, que concedia indulto aos exilados políticos e militares envolvidos em violações aos direitos humanos, fazendo com que nenhum militar envolvido fosse julgado ou condenado por seus atos. Então, após 1985, o regime militar começou o processo de transferência de poder para um 
Kelly Pereira de Lima; Sarah Miglioli; Clóvis Ricardo Montenegro de Lima Da comissão nacional da verdade ao direito à verdade: a validação discursiva das coleções nas bibliotecas

governo civil, evitando uma mudança drástica que pudesse incitar uma revolta do povo e provocasse a acusação contra líderes militares.

As Forças Armadas admitiram oficialmente que possa ter havido tortura e assassinatos, pela primeira vez, em setembro de 2014 , em resposta à Comissão Nacional da Verdade. O documento, assinado pelo Ministro da Defesa, Celso Amorim, menciona que "o Estado brasileiro [...] já reconheceu a ocorrência das lamentáveis violações de direitos humanos ocorridas no passado." (AMORIM, 2014).

Para além da perseguição política, também foi cassada a liberdade de expressão, e se instaurou um período de repressão e censura a todas as publicações e obras que fossem consideradas contra a ideologia propagada pelo regime militar. Como se caracterizou por regime autoritário, a censura era ferramenta de controle e preservação do poder. Com o argumento de manter a moral e os bons costumes, o regime determinou por decreto-lei (BRASIL, 1970) a regulação de informações registradas.

Art. $1^{\circ}$ Não serão toleradas as publicações e exteriorizações contrárias à moral e aos bons costumes quaisquer que sejam os meios de comunicação. Art. $2^{\circ}$ Caberá ao Ministério da Justiça, através do Departamento de Polícia Federal verificar, quando julgar necessário, antes da divulgação de livros e periódicos, a existência de matéria infringente da proibição enunciada no artigo anterior. Art. $3^{\circ}$ Verificada a existência de matéria ofensiva à moral e aos bons costumes, o Ministro da Justiça proibirá a divulgação da publicação e determinará a busca e a apreensão de todos os seus exemplares. Art. $4^{\circ}$ As publicações vindas do estrangeiro e destinadas à distribuição ou venda no Brasil também ficarão sujeitas, quando de sua entrada no país, à verificação estabelecida na forma do artigo $2^{\circ}$ dêste Decreto-lei. Art. $5^{\circ} \mathrm{A}$ distribuição, venda ou exposição de livros e periódicos que não hajam sido liberados ou que tenham sido proibidos, após a verificação prevista neste Decreto-lei, sujeita os infratores, independentemente da responsabilidade criminal. (BRASIL, 1970).

Muitas publicações foram elaboradas durante o período do regime militar com o intuito de propagar os ideais do governo autoritário. 
Diversas obras foram postas em circulação, inclusive livros didáticos, que veiculavam informações sob o ponto de vista da moral conservadora (MARCELINO, 2009).

O caráter democrático e social do papel do bibliotecário, contribuidor do acesso à informação, foi colocado em questão sob a pressão de um regime autoritário como o que o Brasil passou em sua história, no auge da ditadura militar, sob a pressão do governo sobre a circulação de certas informações e a censura de livros.

\section{A VALIDAÇÃO DISCURSIVA DO DESENVOLVIMENTO DE COLEÇÕES}

A terceira Lei da Biblioteconomia de Shiyali Ramamritam Ranganathan institui que para cada livro há um destinatário. Um conjunto de obras compõe uma coleção, que é dedicada a um grupo de faixa etária, social, nível intelectual ou ramo do saber. Isso implica numa identidade, que se constrói para responder e atender os anseios de seus utentes.

Cada ramo do saber possui um arcabouço teórico e este aporte se faz presente e eminente nas bibliotecas. A gênese de uma coleção é constituída por produções de um colégio intelectual que fundamentam e compõem as bases teóricas de um conhecimento.

As bibliotecas não podem ser consideradas inertes, mero local de estagnação para apreensão do saber, e sim espaços políticos, sociais, de cidadania e de conflito. Os conceitos, juízos, ideias e perspectivas materializadas em documentos, propiciam embates e concordâncias de verdades. Numa mesma prateleira ou estante podemos encontrar ideias convergentes e divergentes de autores que participam da mesma comunidade intelectual.

Sempre inserida num panorama sócio-histórico, a seleção e desenvolvimento de coleções é atividade primórdio das bibliotecas. $\mathrm{Na}$ Antiguidade "[...] as bibliotecas eram arquivos dos reis, para uso 
próprio." (PINHEIRO, 2006, p. 34). As grandes bibliotecas da Antiguidade como da Mesopotâmia, de Pérgamos e de Alexandria são "[...] fruto de uma política sistemática de aquisições, que busca a completude, a acumulação e todas as formas de saber e de criação confiadas à escrita." (JACOB, 2000, p. 51).

As bibliotecas tiveram que repensar no processo de formação e constituição de suas coleções, no final da década de 60 e início da de 70 a partir do "Movimento para o Desenvolvimento de Coleções" na biblioteconomia internacional, "Boa parte dos bibliotecários começaram a preocupar-se com suas coleções, buscando desenvolvê-las, selecioná-las, expurgá-las, enfim, transformá-las em alguma coisa mais coerente." (VERGUEIRO, 1989, p. 11).

As políticas de desenvolvimento de coleção surgem em um cenário onde a biblioteca passa de acumuladora de obras para um espaço comum de algumas verdades. A produção intelectual é inversamente proporcional ao espaço físico disposto pelas bibliotecas. A falta de verba, espaço e recursos humanos direciona a escolhas de títulos que podem contribuir, atualizar ou questionar o acervo instituído.

O modelo de processo de desenvolvimento de coleções elaborado por G. Edward Evans (apud VERGUEIRO, 1989), ainda hoje é aplicado nas bibliotecas, compreendendo as políticas de seleção, seleção, aquisição, desbastamento, avaliação e estudo da comunidade. A construção de uma política implica em estabelecer um conjunto de normas que irão reger as rotinas de desenvolvimento de coleção (FIGUEIREDO, 1993); estabelecer de forma clara e delineada os objetivos e metas, os quais se propõem a alcançar com base na coleção existente e de acordo com a instituição e a comunidade; avaliar o grau de força e fraqueza os recursos existentes e determinar a profundidade e o escopo da politica de informação (RESOURCES AND TECHINCAL SERVICES DIVISION apud FIGUEIREDO, 1993). Dessa forma O desenvolvimento de coleção possui caráter cíclico e ininterrupto. 
Considerando esse caráter cíclico, a política de desenvolvimento de coleções está diretamente atrelada à relação entre ética informacional. Envolve as escolhas que são feitas ou que têm de ser feitas. Entretanto há uma grande distinção entre a ética prática e teórica. Day (2015) aborda as questões éticas, que devem ser analisadas pelas ordens morais e o espírito racional humano, que muitas vezes esbarra na ética e moral já estabelecida. Harré (1993 apud DAY, 2015) denomina "ordens morais" como conjunto de expectativas normativas de papéis sociais e regras de comportamento. Para Day (2015) ocupamos vários papéis sociais morais (pai, irmão, amigo, empregado etc.) e respondemos de forma diferente conforme a situação, temos responsabilidades sobre nossas respostas e ações. Os dilemas éticos são confrontos de aplicar ou não as regras morais. Nem sempre agimos conforme as regras, transgredimos. Ordens morais são culturalmente construídas e culturalmente, são aprendidas, produtos de experiência e desenvolvimento psicológico. As escolhas éticas às vezes ocasionam uma mudança histórica para a pessoa que faz a escolha. Um bibliotecário deve agir de forma socialmente responsável mesmo no fornecimento de recursos de informação. Agir com responsabilidade ética e não apenas mecanicista para seguir uma regra determinada (DAY, 2015).

As bibliotecas ainda não se deram conta da importância de formalizar suas políticas, instrumento normativo e discursivo. Como a "[...] falta de uma política definida para o desenvolvimento do acervo é terreno fértil para o exercício da censura e da autocensura, pois nada existirá para impedir a atividade de censores externos e internos." (VERGUEIRO, 1987, p. 25). Para fins de exemplificação, considera-se a censura $o$ ato de análise crítica às produções literárias e artísticas, antes de serem expostas ao público, conforme um regime político, religioso ou moral atuante.

Vergueiro (1987) eleva a questão da postura do bibliotecário, quanto selecionador e responsável pelo desenvolvimento da coleção, 
lidando com a censura e com a liberdade intelectual do usuário. A liberdade intelectual é um direito assegurado e qualquer restrição que se faça a ela é um atentado digno de protesto e reação. Entretanto em termos práticos a questão é mais complexa e exige atitudes mais expressivas:

[...] contra as pressões que vêm de parte de autoridades governamentais, de associações civis ou de indivíduos que se sentem no direito de exigir a retirada, da coleção da biblioteca, de livros e outros materiais que veiculem conceitos dos quais discordam e que não gostariam de ver disseminados entre os outros membros da comunidade. (VERGUEIRO, 1987, p. 21).

Existem três tipos de censura, a governamental; pressão individual ou de grupo; e autocensura, sendo "[...] muito mais fácil lidar com os dois primeiros tipos de censura do que com o terceiro, pois naqueles existem apenas duas alternativas: ou se luta contra a censura ou se compactua com ela." (EVANS, 1979 apud VERGUEIRO, 1987, p. 24). Como parâmetro de resistência e luta contra a censura e a favor da liberdade intelectual nas atividades e serviços dos bibliotecários, podemos nos conduzir pela Library Bill of Rights (Declaração de Direitos da Biblioteca).

A American Library Association (ALA) publica o Manual de Liberdade Intelectual para responder a questões práticas que enfrentam os profissionais da informação na aplicação dos princípios da liberdade intelectual nos serviços da biblioteca. Afirma que todas as bibliotecas são fóruns de informação e ideias, apresentando uma visão geral dos problemas de hoje e os novos desafios, da Internet à privacidade e confidencialidade. A publicação não garante por si só que os direitos dos bibliotecários e os usuários nunca serão desafiados ou que as dificuldades não irão surgir, mas aderir a estes princípios em cada biblioteca é absolutamente essencial se profissionais da informação e os cidadãos pretendem desfrutar de todos os benefícios da liberdade de expressão. 
Kelly Pereira de Lima; Sarah Miglioli; Clóvis Ricardo Montenegro de Lima Da comissão nacional da verdade ao direito à verdade: a validação discursiva das coleções nas bibliotecas

Aprovada em 1939 pelo Intellectual Freedom Committee, a Library Bill of Rights (Declaração de Direitos da Biblioteca) elege princípios básicos que devem reger os serviços de todas as bibliotecas. A declaração teve algumas modificações e a última data 1996. No período da $2^{\mathrm{a}}$ Guerra Mundial, imperava um período de grande ameaça à liberdade intelectual, onde governos realizam supressão de tudo o que considerava contrário aos interesses, tendo a Declaração papel importante como instrumento de resistência às pressões.

As questões surgem a respeito da aplicação de princípios para práticas específicas da biblioteca. As políticas fundamentais devem orientar seus serviços e listam 6 (seis) princípios básicos:

I. Livros e outros recursos da biblioteca devem ser providos para o interesse, informação e esclarecimento de todas as pessoas da comunidade a ser servida. Os materiais não devem ser excluídos devido à origem, fundo, ou pontos de vista daqueles contribuindo para a sua criação. II. As bibliotecas devem prover materiais e informações que apresentam todos os pontos de vista sobre temas atuais e históricos. Os materiais não devem ser proibidos ou removidos por causa da desaprovação partidária ou doutrinária. III. As bibliotecas devem desafiar a censura no cumprimento de sua responsabilidade de prover informação e esclarecimento. V. As bibliotecas devem cooperar com todas as pessoas e grupos preocupados em resistir à restrição da livre expressão e livre acesso às ideias. V. O direito de uma pessoa a usar uma biblioteca não deve ser negado ou abreviada por causa de origem, idade, antecedente, ou pontos de vista. VI. Bibliotecas devem se tornar espaços de exposição e salas de reuniões disponíveis para o público que servem; devem fazer tais instalações disponíveis numa base de igualdade, independentemente das crenças ou filiações de indivíduos ou grupos que solicitam a sua utilização. (AMERICAN LIBRARY ASSOCIATION, 1996).

O desenvolvimento de coleções nesse sentido é muito mais que meramente fazer escolhas aleatórias para compor o acervo, deve estar a par do contexto da comunidade que integra. A técnica de constituir e organizar uma coleção em uma biblioteca requer conhecer tanto os 
Kelly Pereira de Lima; Sarah Miglioli; Clóvis Ricardo Montenegro de Lima Da comissão nacional da verdade ao direito à verdade: a validação discursiva das coleções nas bibliotecas

livros como as pessoas o bastante para fornecer e recomendar os livros apropriados para os seus leitores (FIGUEIREDO, 1993).

Segundo Figueiredo (1993), as políticas de desenvolvimento de coleções envolvem princípios básicos: a coleção de biblioteca contribui com informação, devendo ir ao encontro das demandas de informação feitas pelos indivíduos e pela sociedade, em segundo, a biblioteca deve contribuir para um programa de educação pública fornecendo informação e conhecimento, essencial para a função educacional da coleção da biblioteca. De fato, aos bibliotecários de biblioteca "[...] cabe o papel de educadores, e a importância e o valor da sua tarefa são inestimáveis." (FIGUEIREDO, 1993, p. 19).

Para tanto, é condição sine qua non que sejam traçados os objetivos gerais da biblioteca, relacionados com a instituição e a comunidade que a ela serve, para de acordo com estes objetivos, ser traçada a política de seleção da biblioteca (FIGUEIREDO, 1993).

Considera-se o que os livros podem significar para o desenvolvimento individual: na formação do caráter, na ativação da inteligência, no enriquecimento dos recursos, no aprofundamento da sensibilidade. Eles oferecem material para a formação do caráter através do conhecimento e do pensamento. A formação do caráter é um processo contínuo e inconsciente de autoeducação na escola diária da vida; quando a mente alcança o uso e o controle destes fios, todo o panorama da vida no mundo, passada e presente, se torna constantemente mais variada e interessante, enquanto, ao mesmo tempo, os poderes de reflexão e julgamento da própria mente são exercitados e fortalecidos. (FIGUEIREDO, 1993, p. 33).

A política de seleção é, então, um conjunto de diretrizes e normas que visa estabelecer ações, delinear estratégias gerais, determinar instrumentos e delimitar critérios para facilitar a tornada de decisão na composição e desenvolvimento de coleções em consonância com os objetivos da instituição e os usuários do sistema.

A seleção deve ser realizada por uma comissão composta de uma representação dos usuários, da organização mantenedora e do 
Kelly Pereira de Lima; Sarah Miglioli; Clóvis Ricardo Montenegro de Lima Da comissão nacional da verdade ao direito à verdade: a validação discursiva das coleções nas bibliotecas

pessoal que atende aos usuários e que, portanto, conhece a comunidade. A política de seleção deve ser flexível e atualizada, e expressar de forma a facilitar as decisões e a justificar a incorporação ou não de determinados itens (LIMA; FIGUEIREDO, 1984).

A política de seleção pode se transformar em dispositivo social e político, proporcionando fundamentos para as decisões nas admissões ou não de uma obra, não sendo pressionado ou induzido pelo modismo, tendência ou hegemonia cultural, além de possibilitar abertura para os discursos dos grupos minoritários, logo que,

As ideias da classe dominante são, em todas as épocas, as ideias dominantes, ou seja, a classe que é o poder material dominante da sociedade é, ao mesmo tempo, o seu poder espiritual dominante. A classe que tem à sua disposição os meios para a produção material dispõe assim, ao mesmo tempo, dos meios para a produção espiritual, pelo que lhe estão assim, ao mesmo tempo, submetidas em média as ideias daqueles a quem faltam os meios para a produção espiritual. [...] Os indivíduos que constituem a classe dominante também têm, entre outras coisas, consciência, e daí que pensem; na medida, portanto, em que dominam como classe e determinam todo o conteúdo de uma época histórica, é evidente que o fazem em toda a sua extensão, e portanto, entre outras coisas, dominam também como pensadores, como produtores de ideias, regulam a produção e a distribuição de ideias do seu tempo; que, portanto, as suas ideias são as ideias dominantes da época. (MARX; ENGELS, 2002, p. 56).

Há que se evitar que a coleção seja mera representação das ideias dominantes em cada período sócio-histórico, podendo se tornar vulneravelmente manipulável. Se as ideias dominantes são as ideias da classe dominante, como Marx e Engels (2002) afirmaram, a Biblioteca deve ser o espaço em que o silêncio dos dominantes é quebrado.

Não se pode permitir que a Biblioteca se torne a não voz dos vencidos, caindo nas armadilhas da história dos vencedores e de uma revisão subserviente da coleção. Os livros que vão para a estante compõem o acervo e não podem representar a história contada pelos 
vencedores, cabendo ao bibliotecário quebrar o silêncio e desvelar os segredos que permanecem em esquecimento reconfortante (DECCA, 2004).

O desenvolvimento da coleção das bibliotecas não pode ficar à disposição de modismos e tendências, ficando subjugada à hegemonia cultural de determinada época. O conceito formulado por Gramsci (1978) para descrever o tipo de dominação ideológica descreve a conjuntura que muitas organizações se submetem, mantendo em seus acervos obras representativas de ideologias dominantes em coleções obtusas de realidade.

Sabe-se que durante a exposição ao regime militar, muitas bibliotecas brasileiras se tornaram alvos fáceis para a imposição de obras publicadas pelo Exército Brasileiro (MARCELINO, 2009; SILVA, 2014). Muitas bibliotecas tiveram que incluir em seus acervos materiais produzidos pelo governo disseminando uma ideologia da "boa moral e bons costumes", ou retirar livros sob a censura do regime.

O documento da política de coleções deve ser o resultado de interações entre os bibliotecários e aqueles a quem a mesma se destina, representando a validação discursiva da verdade. Por intermédio de comissões deliberativas ou consultivas, instituídas como uma modalidade a trazer maior número de vantagens, deve representar o canal de comunicação e de divisão de responsabilidade pela seleção com a própria comunidade, trazer uma forma de participação mais ativa na gestão (VERGUEIRO, 1989), instituir um dispositivo de resistência do trabalho conjunto a ordens predominantes, que vão de encontro com a liberdade intelectual e de acesso.

A composição de comissões deliberativas torna a biblioteca um espaço de esfera pública, pela integração de representantes da comunidade na tomada de decisão colegiada e coletiva (VERGUEIRO, 2010), valendo-se do conceito do agir comunicativo de Habermas, uso da linguagem natural como meio de interação social nas coordenações das ações conduzidas pela força consensual do entendimento. 
O esboço do agir comunicativo é um desdobramento da intuição segundo a qual o telos de entendimento habita na linguagem. O conceito de "entendimento" possui conteúdo normativo, que ultrapassa o nível da compreensão de uma expressão gramatical. Um falante entende-se com outro sobre uma determinada coisa. $E$ ambos só podem visar tal consenso se aceitarem aos proferimentos por serem válidos, isto é, por serem reconhecimento aberto à crítica. (HABERMAS, 1990, p. 77).

A seleção das verdades que integrarão 0 acervo pode reestabelecer e reconstruir a história de uma sociedade, no momento em que "[...] seus participantes regulam sua pertença a grupos sociais e garantem a solidariedade [...]" (HABERMAS, 1990, p. 96) aos direitos humanos e a dignidade humana, dando voz ao silêncio dos vencidos, oprimidos e minoritários.

[...] as condições de verdade são o critério para saber se um proferimento preenche ou não sua função de representação; todavia, o preenchimento da função interativa e expressiva da linguagem mede-se através de condições da autorização e da sinceridade, que são análogas à verdade. (HABERMAS, 1990, p. 80).

Foucault tem essa concepção da constituição do ser, elaborada por uma ética, que compreende o falar a criticidade, veracidade, para a além do irônico crítico.

A parresía é, portanto, em duas palavras, a coragem da verdade naquele que fala e assume o risco de dizer, a despeito de tudo, toda a verdade que pensa, mas é também a coragem do interlocutor que aceita receber como verdadeira a verdade ferina que ouve. (FOUCAULT, 2014, p. 13).

A ideia da coragem da verdade permite pensar a informação como algo criativo, dentro de uma ação social. A parresía é um agir na coragem de falar. E a informação nesse contexto é uma informação verdadeira, que se constrói no sentido da verdade, em função da verdade. 
Nesse sentido, propõe-se que as bibliotecas revejam sua política de desenvolvimento de coleções, de modo que, pelo caminho aberto pelas diretrizes da Comissão Nacional da Verdade, num movimento paralelo a fim de esclarecer os fatos e as circunstâncias históricas do país, possam representar a adoção de medidas para prevenir violação de direitos humanos, assegurar sua não repetição, promover a efetiva reconciliação nacional e a reconstrução da história, repreendendo danos aos direitos humanos.

Com Foucault, observamos a importância da parresía, ou seja, da coragem da verdade, de dizer a verdade sobre si mesmo. Com isso, vemos como as bibliotecas precisam ser campo de revisão de suas políticas de desenvolvimentos de coleções, para que elas representem a verdade e a democracia, sendo as bibliotecas mesmas representações da ética e dignidade. Através da revisão de suas políticas, visando o compromisso com a verdade e a reconstrução histórica, propõe-se o olhar para as obras retiradas por meio da censura de um regime ditatorial e as incluídas como meio de disseminação de ideais políticos.

\section{CONSIDERAÇÕES FINAIS}

Este artigo abordou as questões da veracidade no âmbito de uma eticidade, traçando uma abordagem teórica por meio de Habermas e Foucault. Através de Habermas, o marco teórico se utiliza da aprendizagem intersubjetiva por meio da linguagem, ou seja, no discurso residente na possibilidade do entendimento mútuo e da prevalência da verdade.

A reconstrução histórica como processo liderado por iniciativa da Comissão Nacional da Verdade, através dos documentos como informação registrada, levanta a possibilidade de reconstrução histórica de um passado submetido a graves violações dos direitos humanos.

Fomentar espaços de interações sociais e políticos na biblioteca, estabelecer consenso do entendimento nas coordenações das ações 
entre a equipe administrativa e a sociedade, e ter coragem de dizer e procurar a verdade, são posturas que compõe a ética de um profissional que é solidário com a dignidade humana de cada integrante de sua comunidade.

O profissional da informação tem uma responsabilidade social, por ser a incorporação da alma de uma sociedade e de seu pressuposto democrático. Sua relevância encontra-se no fato de reger o potencial inerente às coleções de maneira a promover a verdade, sem a qual sua atuação perderia o viés moral e ético.

\section{REFERÊNCIAS}

AMERICAN LIBRARY ASSOCIATION. Library Bill of Rights. 1996. Disponível em: <http://www.ala.org/advocacy/intfreedom/librarybill>. Acesso em: 6 jul. 2015

AMORIM, Celso. Oficio no 10944 de 19 de setembro de 2014 do Gabinete do Ministério da Defesa Comissão Nacional da Verdade. Brasília, 2014.

BANNELL, R. I. Do "círculo mágico da linguagem" à realidade: uma análise crítica da pragmática da aprendizagem de Jürgen Habermas. Ethica, Rio de Janeiro, v. 16, n. 1, p. 69-113, 2009.

BRASIL. Decreto-Lei $\mathbf{n}^{\circ}$ 1.077, de 26 de janeiro de 1970. Disponível em: <http://www.planalto.gov.br/ccivil_03/Decreto-Lei/19651988/Del1077.htm> Acesso em: 28 de junho de 2015.

BRASIL. Lei $\mathbf{n}^{0}$ 12.528, de 18 de novembro de 2011. Disponível em: <http://www.planalto.gov.br/ccivil_03/_Ato20112014/2011/Lei/L12528.htm> Acesso em: 28 de junho de 2015.

BRIET, S. Qu'est-ce que la documentation? Paris: Édit - Éditions Documentaires Industriales et Techniques, 1951. 48 p. Disponível em: $<$ http://martinetl.free.fr/suzannebriet/questcequeladocumentation/briet.pd f/>. Acesso em: 10 nov. 2009.

BRITO, A. B. de. Justiça transicional e uma política de memória: uma visão global. Revista Anistia Política e Justiça de Transição, Brasília, n. 1, p. 56-82, jan./jun. 2009. 
BUCKLAND, M. K. Information as thing. Journal of the American

Society for Information Science. v. 45, n. 5, p. 351-360, 1991.

DAY, Ronald. Information ethics: normative and critical perspectives.

Rio de Janeiro, 2015. (Palestra proferida no Programa de Pós-

Graduação em Ciência da Informação, IBICT, na disciplina Ética e Informação).

DECCA, Edgar Slavadori. 1930: o silêncio dos vencidos. Campinas, SP: Brasiliense, 2004.

FIGUEIREDO, Nice Menezes de. Desenvolvimento e avaliação de coleções. Rio de Janeiro: Rabiskus, 1993.

FOUCAULT, Michael. A coragem da verdade. São Paulo: Martins Fontes, 2014.

GRAMSCI, Antonio. Concepção dialética da história. Rio de Janeiro:

Civilização

Brasileira, 1978.

HABERMAS, Jürgen. Pensamento pós-metafísico: estudos filosóficos. Rio de Janeiro: Tempo Brasileiro, 1990.

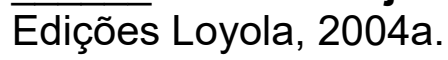

Verdade e justificação: ensaios filosóficos. São Paulo:

. Consciência moral e agir comunicativo. Rio de Janeiro:

Tempo Brasileiro, 1989.

A ética da discussão e a questão da verdade: estudos de teoria política. 3. ed. São Paulo: Martins Fontes, 2004b.

JACOB, Christian. Ler para escrever: navegações alexandrias. In: BARATIN, Marc; JACOB, Christian (org.). O poder das bibliotecas: a memória dos livros no Ocidente. Rio de Janeiro: Ed. UFRJ, 2000.

LIMA, Regina Célia Montenegro de; FIGUEIREDO, Nice Menezes de. Seleção e aquisição: da visão clássica à moderna aplicação de técnicas bibliométricas. Ci. Inf., Brasília, v, 13, n. 2, p. 137-50, jul./dez. 1984.

MACHADO, Ana Maria Nogueira. Informação e controle bibliográfico: um olhar sobre a cibernética. São Paulo: Editora UNESP, 2003.

MARCELINO, Mariane A. A ditadura militar e os livros didáticos de história. Criciúma: UNESC, 2009.

MARX, Karl; ENGELS, Friedrich. A Ideologia Alemã. São Paulo: Centauro, 2002. 
MURGUIA, Eduardo Ismael. Documento e instituição: produção, diversidade e verdade. In: FREITAS, Lídia S.; MARCONDES, Carlos H.; RODRIGUES, Ana Célia (Org.). Documento: gênese e contexto de uso. Niterói, RJ: EdUFF, 2010. p. 123-140.

ORTEGA, Cristina Dotta; LARA, Marilda Lopes Ginez de. A noção de documento: de Otlet aos dias de hoje. DataGramaZero - Revista de Ciência da Informação, Rio de Janeiro, v. 11, n. 2, artigo 3, abr. 2010. Disponível em: <http://www.dgz.org.br/abr10/Art_03.htm>. Acesso em: 19 jun. 2015.

PINHEIRO, Ana Virginia. Produção do Registro do Conhecimento: planos de aulas, Rio de Janeiro: [s.e.], 2006.

SILVA, Marcelly Chrisostimo de Souza. Censura durante a ditadura militar no Brasil e seu impacto no exercício da Biblioteconomia: um estudo sobre a atuação dos conselho profissionais. Rio de Janeiro: UNIRIO, 2014.

VERGUEIRO, Waldomiro. Censura e seleção de materiais em bibliotecas: o despreparo dos bibliotecários brasileiros. Ci. Inf., Brasília, 16 (1), p. 21-26, jan./jun. 1987. Disponível em: <http://revista.ibict.br/ciinf/index.php/ciinf/article/view/1569/1504>. Acesso em: 26 jun. 2015.

.Desenvolvimento de coleções. São Paulo: Polis, 1989.

Seleção de materiais de informação. 3. ed. Brasília: Briquet de Lemos Livros, 2010.

\section{Title}

The National Commission for Truth to right to the truth: the discursive validation of collections in libraries

\section{Abstract}

Introduction: It analyzes the concept of information, truth and discursive validity. It proposes the formalization and review of the Collection Development Policy in view of the informational ethics, National Commission for Truth and censorship.

Objective: Discusses the position of the acting of the professional information, a socially responsible manner, before a new setting and performance through a collection development policy with ethical decisions of which the truths will be part of the collection.

Methodology: The theoretical framework of this article is to analyze the complexity of the issue of truth by Jürgen Habermas and Michel Foucault, 
under the aegis of the philosophy of language and consciousness, respectively. First will be discuss under the critical focus the relationship between information and truth. Later, the historical facts of the National Truth Commission will be brought, the truth in libraries, and finally, the discursive validation of the collection development.

Results: Through Habermas, using the theoretical framework of intersubjective learning through language, ie, the resident speech at the possibility of mutual understanding and prevalence of truth. Have the courage to say and seek the truth, suggested by Foucault, are postures that make up the ethics of a professional who is sympathetic to the human dignity of each member of their community.

Conclusions: The information professionel has a social responsibility to be the embodiment of the soul of a society and its democratic assumption. Its relevance finds in the fact of govern the potential of these collections in order to promote truth, without which its action would lose the moral and ethical bias.

Keywords: Truth. The National Commission for Truth. Collection Development Policy. Professional information.

\section{Título}

La Comisión Nacional de Verdad al derecho a la verdad: la validación discursiva de colecciones en bibliotecas

\section{Resumen}

Introducción: Se analiza el concepto de información, verdad y validez discursiva. Propone la formalización y revisión de la Política de Desarrollo de la Colección en vista de la ética de la información, la Comisión Nacional para la Verdad y la censura.

Objetivo: Discute la posición de actuar del profesional de la información, de una manera socialmente responsable, delante del nuevo escenário y actuación a través de una política de desarrollo de la colección con las decisiones éticas de los cuales verdades serán parte de la colección

Metodología: El marco teórico de este artículo es analizar la complejidad de la cuestión de la verdad por Jürgen Habermas y de Michel Foucault, bajo la égida de la filosofía del lenguaje y la conciencia, respectivamente. En primer lugar se abordará bajo el enfoque crítico la relación entre la información y la verdad. Más tarde, serán llevados los hechos históricos de la Comisión Nacional de la Verdad, la verdad en las bibliotecas, y finalmente, la validación discursiva de desarrollo de la colección.

Resultados: A través de Habermas, el marco teórico se utiliza del aprendizaje intersubjetivo por médio del lenguaje, así, em el discurso residente en la posibilidad de la comprensión mutua y la prevalencia de la verdad. Tener el valor de decir y buscar la verdad, sugeridas por Foucault, son posturas que componen la ética de un profesional que és solidario con la dignidad humana de cada miembro de su comunidad. 
Kelly Pereira de Lima; Sarah Miglioli; Clóvis Ricardo Montenegro de Lima Da comissão nacional da verdade ao direito à verdade: a validação discursiva das coleções nas bibliotecas

Conclusiones: El profesional de la información tiene una responsabilidad social para ser la encarnación del alma de una sociedad y su asunción democrática. Su importancia radica en el hecho de gobernar el potencial de estas colecciones con el fin de promover la verdad, sin la cual su acción perdería el sesgo moral y ética.

Palabras clave: Verdad. La Comisión Nacional de Verdad. Política de Desarrollo de la Colección. Profesional de la información.

Recebido em: 15/03/2015

Aceito em: 10/09/2015 